\title{
Expressing Gratitude in an EFL Context: The Case of Jordanian Learners
}

\author{
Husam Al-Momani (Corresponding author) \\ Department of English Language and Literature, The Hashemite University, P.O. Box 330127, Zarqa 13133, Jordan \\ E-mail: HusamS@hu.edu.jo \\ Abdullah Jaradat \\ Department of English Language and Literature, The Hashemite University, P.O. Box 330127, Zarqa 13133, Jordan \\ E-mail: abdjaradat@hu.edu.j \\ Nisreen Al-Khawaldeh \\ Department of English Language and Literature, The Hashemite University, P.O. Box 330127, Zarqa 13133, Jordan \\ E-mail: nal-khawaldeh@hu.edu.jo \\ Baker Bani-Khair \\ Department of English Language and Literature, The Hashemite University, P.O. Box 330127, Zarqa 13133, Jordan \\ E-mail: bakribakr@yahoo.com
}

Received: 04-12-2016

Published: 01-07-2017
Accepted: 02-03-2017

doi:10.7575/aiac.ijalel.v.6n.4p.190
Advance Access Published: April 2017

URL: http://dx.doi.org/10.7575/aiac.ijalel.v.6n.4p.190

\begin{abstract}
This study contributes to the existing literature on interlanguage pragmatics by investigating intermediate Jordanian English Foreign Language (EFL) learners' gratitude speech act realization compared to that of native American English speakers. The study considered both aspects of pragmatic competence including pragmalinguistic knowledge (i.e., the use of gratitude strategies) and sociopragmatic knowledge (i.e., the influence of contextual variables). A discourse completion task (DCT) was employed to elicit data from 60 participants divided into two groups: 30 native speakers of American English, and 30 Jordanian EFL learners. Findings revealed that while Jordanian EFL learners and American English native speakers have access to the same gratitude strategies, both groups differed in the order preference of the used strategies and their frequency of use. Furthermore, the two groups showed different patterns in responding to contextual variables (i.e., social power and size of imposition), an indication that different cultural values govern the speech norms of each group. The study concludes with some pedagogical implications that could be implemented in the EFL classroom.
\end{abstract}

Keywords: gratitude, speech acts, interlanguage pragmatics, second language acquisition

\section{Introduction}

The introduction of communicative competence for language learning and testing (Canale \& Swain, 1980) has created a consensus that learning a second language for expressive and communicative purposes involves more than memorizing vocabulary, approximating native-like pronunciation, and mastering the rules of grammar; it also entails acquiring pragmatic competence (Bachman, 1990). This awareness of the prominence of pragmatic competence in learning a second language has given momentum to interlanguage pragmatics (ILP) research, which is the study of how nonnative speakers comprehend, develop, and produce speech acts (Kasper, 1998). A major finding of ILP studies is that even fairly advanced learners might have considerable difficulty acquiring the rules of appropriate language behaviors, often leading them to experience a breakdown in communication known as pragmatic failure (Al-Issa, 2003; Al-Momani, 2009; Al-Shboul, Maros, \& Yasin, 2012; Kasper \& Schmidt, 1996; Rose and Kasper 2001). This is due to speech acts being a major problematic area for the second language learner. Blum-Kulka et al. (1989) described speech acts as "one of the most compelling notions in the study of language use" (p. 1). Billimyer (1990) argued that a major difficulty faced by nonnative speakers in acquiring pragmatic competence is that "speech acts are complex and highly variable, and require that the non-native speakers understand the multiple functions each serves" (p. 2).

Research on ILP is abundant and researchers have examined apologies (Cohen \& Shively, 2007; Rose, 2000), requests (Felix-Brasdefer, 2007; Jalilifar, 2009), refusals (Tada, 2005; Chang, 2011), suggestions (Bordería-García, 2006; Chun, 2009), and expressions of gratitude (Ahar \& Rasekh, 2011; Cheng, 2005; Eisenstein \& Bodman, 1993). Nonetheless, an overview of current studies reveals that to date, ILP researchers have only investigated nonnative speakers (mainly 
English, Chinese, Japanese, Spanish, Korean, and Persian) with limited cultural and linguistic backgrounds (AlMomani, 2009; Al-Shboul et al., 2012). The narrow scope of current studies raises serious questions about the generalizability of their results to other languages. Hence, it is vital to extend the scope of ILP research to encompass more languages and cultures.

\section{Purpose of the Study}

To the researchers' knowledge, there is a lack of research on the difficulties that Jordanian EFL learners may encounter when performing expressions of gratitude speech act in English or any other languages. Accordingly, this study fills an important gap in the ILP literature by investigating advanced Jordanian EFL learners' expressions of gratitude speech act realization compared to native American English speakers. More specifically, this study addresses the following questions:

1. Is there a difference in the total number of gratitude strategies between Jordanian EFL learners and American English native speakers?

2. How do the social variables of (a) social power (equal and lower) and (b) size of imposition (high and low) influence Jordanian EFL learners' use of gratitude strategies compared to that of American English native speakers?

3. How is the use of strategies in gratitude speech act by Jordanian EFL learners compared to that of American English native speakers?

\section{Defining gratitude}

Expressing gratitude is among the most commonly used speech behaviors in everyday interaction. According to Searle's (1976) classification, an expression of gratitude is categorized as an "expressive" speech act which is defined by Eisenstein and Bodman (1986) as "An illocutionary act performed by a speaker which is based on a past act performed by the hearer. This past act benefits the speaker and the speaker believes it to have benefited him or her." (p. 167). From a sociolinguistic viewpoint, a gratitude is a face- threatening act (Brown \& Levinson, 1987) in which the speaker acknowledges the hearer a debt threatening the speaker's negative face. Moreover, it is crucial to emphasize that expressing gratitude is subject to cultural filters. According to Coulmas (1981), "The social relation of the participants and the inherent properties of the object of gratitude work together to determine the degree of gratefulness that should be expressed in a given situation. Differences in this respect are obviously subject to cultural variation." (p. 75). Hence, saying 'thank you' can be problem for second language learners who need to know when and how to thank in the target culture (Bodman \& Eisenstein, 1988; Eisenstein \& Bodman, 1986, 1993).

\section{Literature review}

Studies on the communicative act of gratitude can be divided into three categories: studies within one specific language (mono-cultural), studies between two or more languages (cross-cultural), and studies between languages produced by native and non-native speakers (interlanguage). The current study falls into the second type. Thus, only the studies limited to the scope of the present investigation are reviewed.

In an early study, Eisenstein and Bodman (1993) investigated expressing gratitude speech act behavior of English second language (ESL) learners who represented fifteen linguistic and cultural backgrounds; the largest groups were Chinese, Korean, Japanese, Russian, and Spanish. Data were collected from two groups of participants: 67 advanced ESL learners who served as the experimental group, and 56 native speakers of American English as the L2 control group. The two groups responded to 14 discourse completion test (DCT) items. The DCT results revealed that the learners were successful in responding in a native-like manner to situations requiring simple, phatic, and ritualized expressions of gratitude. Nonetheless, items requiring more complex responses were problematic for many participants who provided inappropriate expressions of gratitude in a significant number of cases. Moreover, there were noticeable differences between learners and native speakers in their responses to contextual variables such as social distance, social power, and size of imposition. Eisenstein and Bodman (1993) concluded that "even advanced learners of English have considerable difficulty adequately expressing gratitude. They need information on the nature of what to say, the language used to express it, and the context in which it is needed." (p. 75).

In another study, Hinkel (1994) examined gratitude speech act perception of 199 advanced ESL learners coming from various linguistic backgrounds, namely, Chinese, Indonesian, Korean, Japanese, Spanish, and Arabic. Native speakers of American English participants comprised L2 control group. Data were collected using a multiple choice questionnaire (MCQ) consisted of 24 situations. The subjects were required to respond to an interaction with an appropriate statement, using one of several choices provided. Results indicated differences between native language groups and native speakers of English in their perception of the appropriateness of certain expressions of gratitude. Although groups rated the choices differently from each other, no significant differences were observed in the selection of gratitude strategies within each group. This is a clear indication of shared cultural values between the members of each group. Hinkel concluded that, it is plausible that subjects transferred their LI pragmatic competence to L2, rather than their exhibited developmental behaviors.

Cheng (2005) looked at Chinese EFL learners' performance of gratitude. The participants were three Chinese ESL learners' groups with different lengths of stay in the United Sates. Native Chinese speakers and American English native speakers were used as control groups. The study sought to find whether there is evidence of pragmatic development in expressing gratitude among Chinese ESL learners with the increase of residence in the United States, and whether there is evidence of pragmatic influence from L1 Chinese in English expressions of gratitude among 
Chinese learners of English. The data were collected through a DCT composed of 8 situations. Results indicted a developmental pattern toward native speakers' norms in expressing gratitude with the increased length of stay while still under the influence of L1, Chinese. With regard to the use of strategies, results showed no significant differences in the use of strategies between the learners' group that stayed in the US and NSE. This indicates pragmatic development due to the length of residence in the target community. Nonetheless, while all three English learners' groups and NSE used significantly more strategies and more words in the high-imposition situations than in the low-imposition situations, social status/power was an influential factor for learners groups that used significantly more strategies in the low-status situations than in the equal-status situations. This is an indication of L1 influence. Additionally, the extensive use of titles and fewer names by the learners and Chinese native speakers in comparison with English native speakers is another sign of L1 influence.

In a pilot study, Farnia and Suleiman (2009) examined Iranian EFL learners' gratitude speech act performance of two proficiency levels; intermediate and advanced. L1 and L2 Data were collected from American native speakers of English and Iranian native speakers of Persian. All groups responded to a DCT containing 14 situations. Two major conclusions were drawn from this study: on a cross-cultural level, Iranian and American native speakers used the same type of strategies; however, the difference was in the frequency of use of these strategies. Moreover, American respondents resorted to fewer strategies in expressing gratitude in comparison with Iranian respondents. On the interlanguage level, the study found no correlation between language proficiency and the use of strategies. Despite the importance of this study as it introduced a new linguistic group to interlanguage studies, the obtained results should be interpreted with care. It might be the case that the low number of participants in each group, 10 participants, did not allow statistical analyses to take place.

Moreover, in the Iranian context, Ahar and Rasekh (2011) explored the strategies Persian EFL learners use for expressing gratitude compared with Persian native speakers and English native speakers. The findings of the study showed that English learners intended their responses to be polite but they were not appropriate to the social norms of American society. For example, the Persian EFL speakers' expressions for their boss and their neighbor's son were quite similar with respect to the type and number of strategies employed. It seems that responses of learners' group deviated from their native language norms and target culture norms as they took their own patterns. The findings highlight the necessity of equipping EFL learners with the linguistic strategies that are appropriate to convey the intended meanings in various social contexts.

Generally, previous studies on gratitude speech act indicate that language learners seem to have access to the same repertoire of gratitude strategies as native speakers. However, the manner in which these features are organized and affected by social variables (e.g., social power, social distance, and size of imposition) is subject to cultural filters which reflect different cultural values.

\section{Methodology}

\subsection{Participants}

Sixty participants divided into two groups took part in this study: 30 Jordanian EFL (JEFL) learners, 12 males and 18 females; and 30 native speakers of American English (AE), 14 males and 16 females. The JEFL participants were recruited from the Hashemite University (HU), Jordan, and the AE participants from an American University in Pennsylvania. All the participants were undergraduate students between the ages of 19 and 25. To avoid the possibility of having multiple proficiency levels among the JEFL participants, only fourth-year English language students participated in this study. Participants' living abroad experience was also taken into consideration. Cross-cultural communication studies (e.g., Clyne, Ball, \& Neil, 1991) have indicated that nonnative speakers living abroad, under the influence of the target language and culture, may no longerabide by their home cultural norms when using their L1. Accordingly, participants who had lived abroad for 4 months or more were excluded from this study.

\subsection{Instrument and procedure}

Data for the current investigation were collected using a Discourse Completion Task (DCT) that was adopted from Cheng (2005). Although the DCT had been previously used in several cross-cultural and interlanguage studies on expressing gratitude speech act (e.g., Al-Khawaldeh, 2014; Farnia \& Suleiman, 2009), the original DCT, consisted of 14 situations, was piloted to six Jordanian learners to ensure its appropriateness for the current population. Based on the pilot study, eight gratitude-eliciting situations were chosen. Minor modifications were made to some situations to ensure cross-cultural compatibility of the situations to the participants of this study.

Each item in the DCT consisted of a situational description that specified a setting followed by a blank space in which the participants need to provide the appropriate linguistic form of gratitude as though they were the speakers engaging in real-life interaction (see Appendix A). The design of each situation was based on systematic variation of three contextual variables: social status (i.e., power), familiarity (i.e., social distance), and degree of imposition (i.e., size of favor), which have been crucial in determining speech-act behaviors in cross-cultural pragmatics research(Beebe \& Takahashi, 1989; Brown \& Levinson, 1987; Cheng, 2005). Table 1 clarifies the final version of the DCT according to the variable combinations. 
Table 1. DCT situations based on social variables

\begin{tabular}{llll}
\hline Situation & $\begin{array}{c}\text { Social power } \\
\text { (status) }\end{array}$ & $\begin{array}{c}\text { Familiarity } \\
\text { (social distance) }\end{array}$ & $\begin{array}{c}\text { Imposition } \\
\text { (size of favor) }\end{array}$ \\
\hline 1. Class notes & Equal & Familiar & Low \\
2. Borrowing a book & Lower & Familiar & Low \\
3. Paper extension & Lower & Unfamiliar & High \\
4. fixing a computer & Equal & Unfamiliar & High \\
5. Recommendation letter & Lower & Unfamiliar & Low \\
6. Scattered notes & Equal & Unfamiliar & Low \\
7. Moving items & Equal & Familiar & High \\
8. FedEx & Lower & Familiar & High \\
& & & \\
\hline
\end{tabular}

A colleague who is an applied linguist and a current instructor at the American university administered the study instrument to the AE group, and the researcher administered the study instruments to the JEFL group at the HU. Through e-mail and telephone contact, the researcher ensured that the instructor understood the data collection protocol. The students who agreed to participate were given an informed consent form to read and sign. The participants were asked to read each situation carefully and imagine that they are in the same situation. Then, respond naturally using the same language they would use in their daily interaction. It means that they should not give their ideal responses but rather responses that they used in everyday interactions.

\subsection{Data analysis}

Data from the DCT were coded in accordance with a coding scheme proposed by Cheng (2005) (See Appendix B). The scheme is based on eight gratitude strategies: thanking, appreciation, repayment, recognition of imposition, apology, positive feeling, other, and alerter. The coded data were entered into SPSS program; both descriptive and inferential statistics were used to interpret the results and determine if the differences between Jordanian EFL and AE groups were statistically significant.

\section{Results}

This chapter presents the JEFL and AE participants' performance of gratitude speech act based on the results of the DCT. Overall, as shown in Figure 1, The JEFL participants used more gratitude strategies $(n=603)$ than the AE participants $(n=561)$. On average, the JEFL group used $(M=2.51)$ strategies and the AE group used $(M=2.34)$ strategies. Despite this difference, chi-square test analysis of JEFL and AE participants' overall use of gratitude strategies showed no significant difference between the two groups (see Table 4).

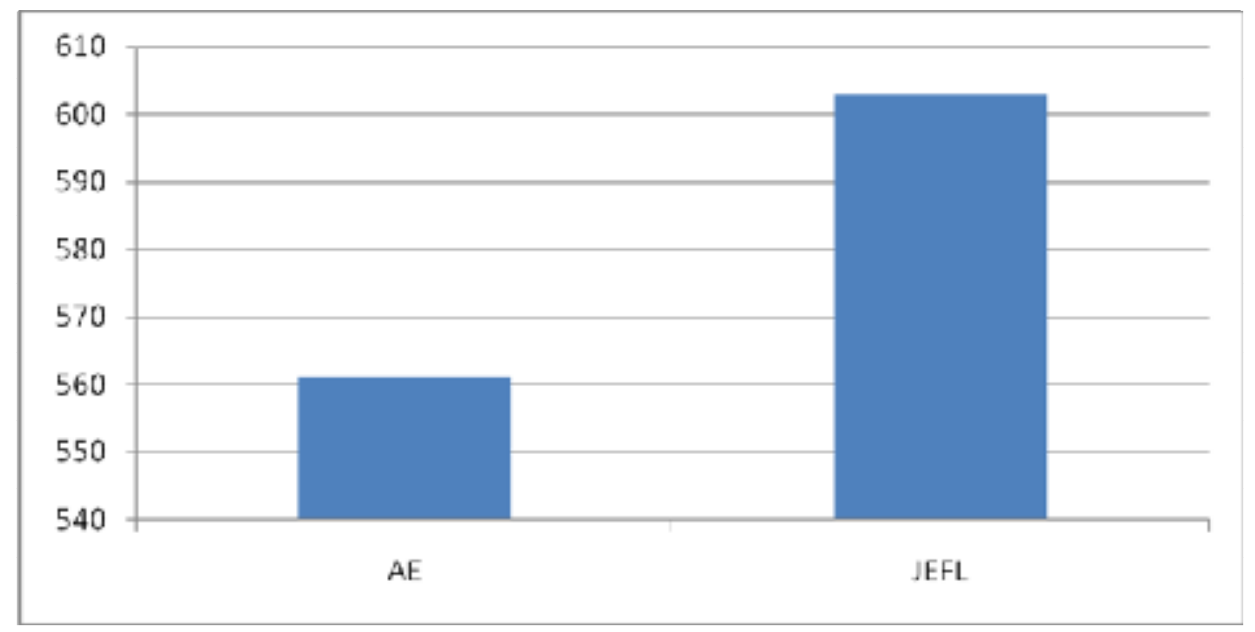

Figure 1. Frequency of all strategies by AE and JEFL participants

The effect of contextual variables of social power and size of imposition on the two groups' use of gratitude straggles was also examined. Chi-square test analysis of equal vs. low power situations indicated that the JEFL participants used significantly more gratitude strategies in low power situations $56.4 \%$ than in equal power $43.6 \%$. In contrast, social power did not seem to influence the AE participants' use of gratitude strategies in any of these situations (see Table 2). 
Table 2. Influence of social power on gratitude strategies

\begin{tabular}{lcccccc}
\hline Group & \multicolumn{2}{c}{ Low Power } & \multicolumn{2}{c}{ Equal Power } & \multicolumn{2}{c}{ Low vs. Equal } \\
& $\%$ & $\mathrm{~N}$ & $\%$ & $\mathrm{~N}$ & $\chi^{2}$ & $\mathrm{Sig}$ \\
\hline $\mathrm{AE}$ & $51.9 \%$ & $(291)$ & $48.1 \%$ & $(270)$ & 7.500 & .484 \\
$\mathrm{JEFL}$ & $56.4 \%$ & $(340)$ & $43.6 \%$ & $(263)$ & 29.100 & $.000^{*}$ \\
\hline
\end{tabular}

Regarding size of imposition, Chi-square pair comparisons indicated that the AE participants used significantly more gratitude strategies in high imposition situations $60.4 \%$ than low imposition situations 39.6\%. Although the JEFL participants used more strategies in high imposition situations $51.7 \%$ than low imposition situations $48.3 \%$, this difference did not reach a threshold level of significance $(* p<0.05$, see Table 3$)$.

Table 3. Influence of imposition on gratitude strategies

\begin{tabular}{lcccccc}
\hline Group & \multicolumn{2}{c}{ High Imposition } & \multicolumn{2}{c}{ Low Imposition } & \multicolumn{2}{c}{ High vs. Low } \\
& $\%$ & $\mathrm{~N}$ & $\%$ & $\mathrm{~N}$ & $\chi^{2}$ & $\mathrm{Sig}$ \\
\hline $\mathrm{AE}$ & $60.4 \%$ & $(339)$ & $39.6 \%$ & $(222)$ & 44.667 & $.000 *$ \\
$\mathrm{JEFL}$ & $51.7 \%$ & $(312)$ & $48.3 \%$ & $(291)$ & 6.450 & .689 \\
\hline
\end{tabular}

As Table 4 shows, major differences can be noted in the AE group and the JEFL group order preference of strategies as well as their frequency of use. The AE group used thanking as the most frequent gratitude strategy followed by Appreciation. Positive feeling was ranked third while repayment, recognition of imposition, and alerter strategies were ranked fourth, fifth, and sixth preferred strategies respectively. Apology and other gratitude strategies are the least strategies used by the AE group. Similar to the AE group, thanking strategy was also the most frequent used gratitude formula by the JEFL group. Furthermore, the JEFL group used alerter, positive feeling, repayment, apology, and recognition of imposition strategies as their second, third, fourth, fifth, and sixth preferred strategies respectively, with appreciation and other being the least frequent gratitude strategies utilized by the JEFL group (see Table 4).

Table 4. Percentage, frequency, and chi-Square values of gratitude strategies

\begin{tabular}{|c|c|c|c|c|c|c|}
\hline \multirow[t]{2}{*}{ Gratitude Strategy } & \multicolumn{2}{|l|}{$\mathrm{AE}$} & \multicolumn{2}{|c|}{ JEFL } & \multicolumn{2}{|c|}{ AE-- JEFL } \\
\hline & $\%$ & $\mathrm{~N}$ & $\%$ & $\mathrm{~N}$ & $\chi^{2}$ & Sig \\
\hline Thanking & $36.9 \%$ & (207) & $41.6 \%$ & $(251)$ & 18.300 & $.003 *$ \\
\hline Appreciation & $16.2 \%$ & $(91)$ & $4.1 \%$ & $(25)$ & 38.467 & $.000 *$ \\
\hline Positive feeling & $14.4 \%$ & $(81)$ & $13.8 \%$ & $(83)$ & 4.000 & .911 \\
\hline Apology & $3.2 \%$ & $(18)$ & $6.8 \%$ & $(41)$ & 19.333 & $.000 *$ \\
\hline $\begin{array}{l}\text { Recognition of } \\
\text { imposition }\end{array}$ & $10.3 \%$ & $(58)$ & $6.5 \%$ & (39) & 26.267 & $.000 *$ \\
\hline Repayment & $11.4 \%$ & $(64)$ & $7.0 \%$ & $(42)$ & 28.167 & $.000 *$ \\
\hline Other & $2.7 \%$ & $(15)$ & $3.2 \%$ & (19) & 2.000 & .981 \\
\hline Alerter & $4.8 \%$ & (27) & $17.1 \%$ & $(103)$ & 44.700 & $.000^{*}$ \\
\hline Total & 561 & & 603 & & 8.000 & .333 \\
\hline
\end{tabular}

As shown in Table 4, chi-square comparisons of the eight gratitude strategies revealed significant differences between the JEFL and AE participants in their use of the thanking, appreciation, apology, recognition of imposition, repayment, and alerter strategies. The JEFL participants used the thanking significantly more than the AE participants (e.g., "Thank you so much"; "Thank you so much for letting me keep the books a little longer"; 41.6\% vs. 36.9\%, respectively).The JEFL participants also produced significantly more alerts than the AE participants (e.g., "Professor Johnson "; "Dear friend"; $17.1 \%$ vs. 4.8\%, respectively). The JEFL participants used significantly more apologies than the AE group (e.g., "I'm sorry I couldn't finish the paper in the right time"; "I'm a mess"; 6.8\% vs. 3.2\%, respectively). 
Regarding the other three strategies that showed significant differences, the AE participants used significantly more gratitude strategies than the JEFL participants in their use of appreciation (e.g., " I greatly appreciate your help and time"; ". I really appreciate you taking the time out for writing my recommendation letter"; $16.2 \%$ vs. $4.1 \%$, respectively), recognition of imposition (e.g., " I know you have a ton of things to do"; " You didn't have to do that"; $10.3 \%$ vs. $6.5 \%$, respectively), and repayment (e.g., " Can I take you to dinner when you have time to thank you?"; "I owe you one"; $11.4 \%$ vs. $7.0 \%$, respectively). Table 4 shows no significant differences between the JEFL participants and the AE participants in the use of positive feeling strategy (e.g., " I very much enjoyed the course I took with you"; " That was such a great help"; $13.8 \%$ vs. 14.4\%, respectively) and other strategy (e.g., "Here's the final paper"; ", I don't think I know you. What's your name?"; $3.2 \%$ vs. $2.7 \%$, respectively). It indicates that the learners' group has approximated native speakers' norms of speech in these two strategies.

\section{Discussion}

Findings of the present study are discussed in accordance with the research questions and results presented in the previous section. The first research question addressed the number of gratitude strategies produced by Jordanian EFL learners compared to American English native speakers. Although the difference was not significant, Jordanian learners used more gratitude strategies $(n=603)$ than the American English participants $(n=561)$. These results are in agreement with Al-Khawaldeh (2014) who found that the Jordanian Arabic native speakers produced significantly more gratitude strategies than British English participants to make the uttered gratitude more sincere and tactful. Hence, Jordanian EFL learners' using high number of gratitude strategies indicates a developmental pattern towards American English norms of speech while they are still under the influence of Jordanian Arabic (L1) norms.

The second research question examined the influence of social status (equal and lower) and size of imposition (high and low) on Jordanian EFL learners' use of gratitude strategies compared to that of American English native speakers. Findings indicate that Jordanian EFL learners used significantly more gratitude strategies in low power situations than in equal power situations. In contrast, social status did not seem to influence the American English group's use of gratitude strategies. The influence of size of imposition showed an opposite pattern. While American native speakers used significantly more gratitude strategies in high imposition situations than in low imposition situations, Jordanian EFL learners did not vary their strategies accordingly.

The results of social status are in line with Al-Momani's (2009) study of requests and Al-Issa's (1998) study of refusals. The researchers found that Jordanian learners transferred their Jordanian style patterns into English by selecting different strategies depending on the speaker's social status in relationship to the hearer while American native speakers used more or less similar frequency of strategies regardless of social status. Hence, it can be said that the influence of social status of Jordanian learners can be a result of pragmatic transfer from Arabic language (L1). As for the influence of size of imposition, some researchers (e.g., Al-Khawaldeh, 2014; Eisenstein \& Bodman, 1993; Cheng, 2005) have found that the size of imposition is integral in determining the number and type of gratitude strategies. However, Jordanian learners' lack of sensitivity to imposition is not surprising, as selecting the proper strategy based on contextual variables requires advanced communicative competence in the target language.

The third question discussed the type of gratitude strategies used by Jordanian EFL learners compared with American English native speakers. As expected, Jordanian EFL learners and American English participants used thanking as the most frequent strategy in utilizing gratitude in all the DCT situations. Some researchers (e.g., Ahar \& Rasekh , 2011; Eisenstein \& Bodman, 1993; Cheng, 2005) have also shown that thanking seems to be conventionalized across several languages and cultures; for this, EFL/ESL learners acquire this strategy prior to all other gratitude strategies. Furthermore, the use of alerters as the second most used strategy by Jordanian learners while being ranked sixth by American native speakers is not without cultural significance. While it is acceptable to call professors by their first names in the American culture, the hierarchal structure of the Jordanian society deems it impolite to call a professor with his/her first name. This premise explains Jordanian learners' extensive use of titles (e.g., professor, Dr.) in the situations where they extend gratitude to a professor.

Despite this preference for thanking strategy, chi-square pair comparisons revealed significant differences in six out of eight gratitude strategies. The JEFL participants used thanking, alerts, and apology strategies significantly more than the AE participants. Conversely, the AE participants were significantly higher in their use of appreciation, recognition of imposition, and repayment strategies. Generally, the tendency of Jordanian learners to use more or less strategies than American native speakers raises a critical question: which is better more or less? According to Cheng (2005) and Hinkel (1994), both means of extending thanks can be viewed as inappropriate by native speakers. While using more gratitude strategies than expected can be perceived as exaggerated and somewhat untruthful, the use of less gratitude strategies may also be damaging because speakers failed to show gratitude when it is expected.

\section{Conclusion and pedagogical implications}

This study attempted to investigate Jordanian EFL learners' use of gratitude speech act compared with native American speakers. Generally, the findings show that the learners' group used more gratitude strategies than native American group. Furthermore, learners showed different patterns in responding to the contextual variables (i.e., social power and size of imposition). With regard to stagy type, the findings clearly indicate that while learners and native speakers have access to the same gratitude strategies, the order preference of the used stagiest and their frequency of use were subject to different cultural values that governed the speech norms of the two groups. Consequently, Jordanian learners' 
deviation from native speakers' norm in all the mentioned aspects can be a potential reason for communication breakdown (i.e., pragmatic failure) when communicating with native speakers of English.

Several pedagogical implications could be drawn from the outcomes of this study. The findings could inform the teaching of the speech act of gratitude to Jordanian EFL learners by integrating L2 pragmatic knowledge into the course program (e.g., in videos of role plays of gratitude strategies performed by native speakers). Furthermore, given the importance of the social variables in shaping learners' production of speech acts, instruction could outline different gratitude strategies based on the interlocutor's status, familiarity, and size of imposition. Additionally, learners can be made aware of certain features that persist in their performance of gratitude due to the influence of Jordanian Arabic (L1) speech and cultural norms.

\section{References}

Ahar, V., \& Eslami-Rasekh, A. (2011). The Effect of Social Status and Size of Imposition on the Gratitude Strategies of Persian and English Speakers. Journal of Language Teaching and Research, 2(1), 120-128.

Al-Issa, A. (1998). Socio-pragmatic transfer in the performance of refusals by Jordanian EFL learners: Evidence and motivating factors. Unpublished $\mathrm{PhD}$ dissertation. Indiana University of Pennsylvania, USA.

Al-Khawaldeh, N. N. (2014). Politeness in the linguistic expression of gratitude in Jordan and England: A comparative cross-cultural study. Unpublished PhD thesis. University of Bedfordshire, England.

Al-Momani, H. S. (2009). Caught Between Two Cultures: The Realization of Requests by Jordanian EFL learners. Unpublished Doctoral dissertation. Indiana University of Pennsylvania, USA.

Al-Shboul, Y., Maros, M., \& Yasin, M. S. M. (2012). The Appropriateness in Advice-Giving From a Cross-Cultural Perspective. Arab World English Journal, 3 (3), 106-122.

Bachman, L. (1990). Fundamental considerations in language testing. Oxford,England: Oxford University Press.

Bordería-García, A. M. (2006). The acquisition of pragmatics in Spanish as a foreign language: Interpreting and giving advice. Unpublished doctoral dissertation, The University of Iowa, Iowa, USA.

Billmyer, K. A. (1990). The effect of formal instruction on the development of

sociolinguistic competence: The performance of compliments. Unpublished doctoral dissertation, University of Pennsylvania, USA.

Blum-Kulka, S. (1982). Learning how to say what you mean in a second language: A study of the speech act performance of learners of Hebrew as a second language. Applied Linguistics, 3, 29-59.

Blum-Kulka, S., House, J., \& Kasper, G. (1989). Cross-cultural pragmatics: Requests and apologies. Norwood, NJ:

Ablex.

Bodman, J., \& Eisenstein, M. (1988). May God increase your bounty: The expression of gratitude in English by native and non-native speakers. Cross Currents, 15(1), 1-21.

Brown, P., \& Levinson, S. (1987). Politeness: Some universals of language use. Cambridge, England: Cambridge University Press.

Canale, M., \& Swain, M. (1980). Theoretical bases of communicative approaches to second language teaching and testing. Applied Linguistics, 1, 1-47.

Chang, Y. F. (2011). Refusing in a foreign language: An investigation of problems encountered by Chinese learners of English. Multilingua, 30, 71-98.

Cheng, S. W. (2005). An exploratory cross-sectional study of interlanguage pragmatic development of expressions of gratitude by Chinese learners of English. A doctoral dissertation, University of Iowa, USA.

Chun, M. Y. (2009). Cultural Relativity and Universality of Linguistic Politeness: The Speech Act of Advice. Unpublished doctoral dissertation. Korea University, Korea.

Clyne, M., Ball, M., \& Neil, D. (1991). Intercultural communication at work in Australia: Complaints and apologies in turns. Multilingua, 10, 251-273.

Cohen, A. D., \& Shively, R. L. (2007). Acquisition of requests and apologies in Spanish and French: Impact of study abroad and strategy-building intervention. The Modern Language Journal, 91, 189-212.

Coulmas, F. (1981). "Poison to your soul": Thanks and apologies contrastively viewed. In F. Coulmas (Ed.), Conversational routine (pp. 69-91). The Hague, Netherlands: Mouton.

Eisenstein, M., \& Bodman, J. (1986). "I very appreciate": Expressions of gratitude by native and non-native speakers of American English. Applied Linguistics, 7, 167-185.

Eisenstein, M., \& Bodman, J. (1993). Expressing gratitude in American English. In G. Kasper \& S. Blum-Kulka (Eds.), Interlanguage pragmatics (pp. 61-81). New York: Oxford University Press.

Farnia, M. and Suleiman, R. (2009). An interlanguage pragmatic study of expressions of gratitude by Iranian EFL learners-a pilot study. Malaysian Journal of ELT Research, 5: 108-140. 
Felix-Brasdefer, C. (2007). Pragmatic development in the Spanish as a FL classroom: A cross-sectional study of learner requests. Intercultural pragmatics 4(2). 253-286.

Hinkel, E. (1994). Pragmatics of interaction: Expressing thanks in a second language. Applied Language Learning, 5(1), 53-91.

Jalilifar, A. (2009). Request strategies: Cross-sectional study of Iranian EFL learners and Australian native speakers. English Language Teaching, 2(1), 46-61.

Kasper, G. (1998). Interlanguage pragmatics. In H. Byrnes (Ed.), Learning foreign and second languages (pp. 183208). New York: Modern Language Association.

Kasper, G., \& Rose, K. (Eds.). (2001). Pragmatics in language teaching. Cambridge, England: Cambridge University Press.

Kasper, G., \& Schmidt, R. (1996). Developmental issues in interlanguage pragmatics. Studies in Second Language Acquisition, 18, 149-169. England: Oxford University Press.

Rose, R. (2000). An exploratory cross-sectional study of interlanguage pragmatic development. Studies in Second Language Acquisition, 22, 27-67.

Searle, J. R. (1976). The classification of illocutionary acts. Language in Society, 5, 1-14.

Tada, M. (2005). Assessment of EFL Pragmatic Production and Perception Using Video prompts. Unpublished

Doctoral Dissertation. Temple University, Ohio, USA.

\section{Appendix A. Discourse Completion Task}

\section{Dear Participant:}

The purpose of this study is to investigate cross-cultural differences in speech acts behaviors. This is not a test; there is no right or wrong answer. There are 8 situations in this questionnaire. Please read each situation carefully, and imagine that you are in the same situation. Then, respond naturally using the same language you would use in your daily interaction as if you are talking to a person in front of you.

If you have any questions about any of the situations, please don't hesitate to ask. Thank you for your time.

1. You were sick and missed class last week. You feel better and go to class today. You ask your close friend, who is in the same class, to lend you the notes from last week to make copies. Your friend agrees to lend you the notes. You are giving the class notes back to your friend and you say.....

You:.

2. You borrow a book from Professor Watson for a class project. You are supposed to return the book to Professor Watson tomorrow. However, you need to keep it for another 2-3 days to complete your project. You know Professor Watson very well. So you ask him/her if you can keep the book for a few more days, and he/she agrees. When you return the book to Professor Watson, you say.

You:

3. Tomorrow is the deadline for one of your final papers. You have many other assignments and cannot finish the paper on time. You decide to ask Professor Brown, whom you don't know very well, for an extension. Professor Brown hesitates because it won't be fair to other students in the class, but then he/she agrees to give you an extension. A few days later, you come to the professor's office to hand in the paper and say.

You:.

4. You are having trouble with your computer; it keeps crashing. You know someone at school who knows lot about computers and you ask the person to help you even though the two of you are not close friends. The person hesitates because he/she is very busy, but then agrees to help you, and ends up spending the whole afternoon fixing your computer. After the computer is fixed, you say....

You:.

5. You are graduating this semester and planning to apply for the Master's program at another university. You need to submit three recommendation letters with the application. You have already asked two professors whom you know very well to write letters. Although you don't know Professor Johnson very well, you decide to ask Professor Johnson to write a letter for you because you took a course with him/her last semester. Professor Johnson agrees to write the recommendation letter for you. A few days later, you meet with Professor Johnson and tell you that the recommendation letter is ready. You say.

You:. 
6. You and your classmate, whom you don't know very well, are walking to class. You accidentally drop your papers and notes, which scatter all over the middle of a busy hallway. Your classmate helps you pick up your papers and notes. When your classmate gives the papers and notes to you, you say....

You:

7. You've just bought a T.V. screen and a computer, and you don't have a car to carry them home. You ask a close friend who has a car to help you out. Your friend hesitates because he/she is very busy, but then agrees to help you. After the two of you load your things into the car, drive to your apartment, and then finish carrying everything with you. You say..............

You:

8. You have just found out about a very good financial aid program. You decide to apply, but the deadline is two days away. You ask Professor Smith, whom you know very well, to write a recommendation letter for you. Professor Smith hesitates because she /he is very busy and the deadline is in two days, but he finally agrees to write the letter. When you meet Professor Smith next day, she/he tells you that she/he has sent the letter by FedEx. You say....

You:

\section{Appendix B. Classification of gratitude strategies}

\section{Thanking}

a. thanking only by using the word "thank you" (e.g. Thanks a lot! Thank you very much!)

b. thanking by stating the favor (e.g. Thank you for your help!)

c. thanking and mentioning the imposition caused by the favor (e.g. Thank you for helping me collect the papers.)

\section{Appreciation}

a. using the word appreciate (e.g. I appreciate it!)

b. using the word "appreciate" and mentioning the imposition caused by the favor (e.g. I appreciate the time you spent for me.)

\section{Positive feelings}

a. by expressing a positive reaction to the favor giver (hearer) (e.g. You are a life saver!)

b. by expressing a positive reaction to the object of the favor (e.g. This book was really helpful!)

\section{Apology}

a. using only apologizing words (e.g. I'm sorry)

b. using apologizing words and stating the favor or the fact (e.g. I'm sorry for the problem I made! )

c. criticizing or blaming oneself (e.g. I'm such a fool!)

d. expressing embarrassment (e.g. It's so embarrassing!)

\section{Recognition of imposition}

a. acknowledging the imposition (e.g. I know that you were not allowed to give me extra time!)

b. stating the need for the favor (e.g. I try not to ask for extra time, but this time I need it!)

c. diminishing the need for the favor (e.g. You didn't have to do that!)

\section{Repayment}

a. offering or promising service, money, food or goods (e.g. Next time it's my turn to pay!)

b. indicating indebtedness (e.g. I owe you one! )

c. promising future self-restraint or self-improvement (e.g. It won't happen again!)

\section{Other}

Expressions that do not belong to the mentioned strategies are categorized as other strategies comprising

a. here statement (e.g. Here you are!)

b. small talk (e.g. Your face is very familiar to me but I can't remember where I saw you. What do you study?)

c. leave-taking (e.g. Have a nice day!)

d. joking (e.g. Don't forget to pay again next time)

\section{Alerter}

a. attention getter (e.g. Hey, Hi, Well)

b. title (e.g. Dr., Professor, Sir)

c. name (e.g. John, Mary) 